\title{
STUDY OF L-HISTIDINE HYDROBROMIDE MONOHYDRATE UNDER HIGH PRESSURE AND TEMPERATURE
}

\author{
de Moura, G. M. ${ }^{1},{ }^{2},{ }^{*}$; Carvalho, J. O. ${ }^{1}$; de Azevedo, S. A. ${ }^{1}$; Silva, M. C. D. ${ }^{1}$ and dos \\ Santos, A. O. ${ }^{1}$ \\ ${ }^{1}$ Universidade Federal do Maranhão. Pós-Graduação em Ciência dos Materiais, UFMA, Imperatriz, Maranhão, Brasil \\ ${ }^{2}$ Universidade Federal do Sul e Sudeste do Pará. Instituto de Ciências Exatas e Naturais, UNIFESSPA, Marabá, Pará, Brasil \\ *geanso@gmail.com
}

\begin{abstract}
Organic crystals have been studied to applications as electronic device mainly due nonlinear optical property (NLO). These crystals, when submitted to high pressures, generally, present molecular conformational changes and, in some cases, structural phase transitions. The aims of this work are structural study of L-histidine hydrobromide monohydrate (LHHBr) under high pressure and temperature using X-ray diffraction technique in association with Rietveld refinement. The high pressure X-ray measurement were performed at the XRD1 beam line using $\lambda=0.649133 \AA$ $(19.1 \mathrm{KeV})$, at LNLS by using a DAC (Diamond Anvil Cell), reaching a pressure up to $7 \mathrm{GPa}$. The X-ray measurement varying temperature were performed in a powder diffractometer with $\mathrm{Cu}, \mathrm{K} \alpha$ radiation $(\lambda=1.5418 \AA)$ operating at $40 \mathrm{kV} / 40 \mathrm{~mA}$ with an Anton-Paar TTK450 temperature chamber attached. The samples were heated at 298 up to $463 \mathrm{~K}$ and the patterns were obtained at a $0.02^{\circ}(2 \theta)$ step size and $3 \mathrm{~s} / \mathrm{step}$ in the $10-45^{\circ}(2 \theta)$ range. From the combination of these external factors, we were able to study the phase transition of the crystal which occurs around the temperature of $383 \mathrm{~K}$ from orthorhombic to monoclinic, the lattice parameters of a new phase were determined from powder diffraction by Le Bail method carried out with the GSAS program. The material is stable up to $7 \mathrm{GPa}$.
\end{abstract}

